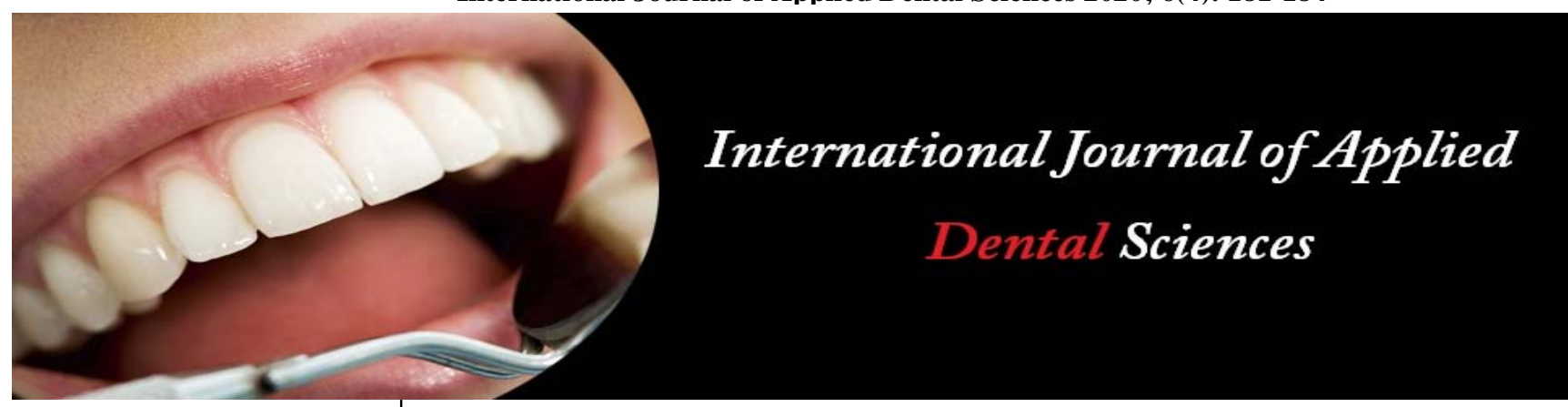

ISSN Print: 2394-7489 ISSN Online: 2394-7497 IJADS 2020; 6(4): 181-184 (C) 2020 IJADS www.oraljournal.com Received: 16-08-2020 Accepted: 21-09-2020

Dr. Janki Ketna Sachin Shah Senior Dentist,

The Dental Arch (Mulund), Mumbai, Maharashtra, India

Dr. Amit Mani

Professor and Head,

Dept. of Periodontology, Rural Dental College PMT, PIMS, Loni, Maharashtra, India

Dr. Nikhat Mohammadi Assistant Professor, Dept. of Periodontology, Rural Dental College PMT, PIMS, Loni, Maharashtra, India

Dr. Parth Yamini Ashok Sejpal Head Dentist,

The Dental Arch (Mulund), Mumbai, Maharashtra, India.

Dr. Prashant Viragi Professor and Head, Dept. of Public Health Dentistry, Rural Dental College PMT, PIMS. Loni, Maharashtra, India

Corresponding Author: Dr. Janki Ketna Sachin Shah Senior Dentist, The Dental Arch (Mulund) Mumbai, Maharashtra, India

\section{Study of influence of advertisements on the purchase of oral health care products on the urban population}

\author{
Dr. Janki Ketna Sachin Shah, Dr. Amit Mani, Dr. Nikhat Mohammadi, \\ Dr. Parth Yamini Ashok Sejpal and Dr. Prashant Viragi
}

DOI: $\underline{\text { https://doi.org/10.22271/oral.2020.v6.i4c.1065 }}$

Abstract

These days advertisements have formed an integral part of our lives. Every time we see around, we tend to bump into advertisements of varied products, at varied sites. There is also a surge in focus about oral health and to serve this demand and incur profits, companies are coming up with variety of products pertaining to different requirements of their respective target population. In order to promote the products, they produce, companies use advertising as one of their ace tools. It is quintessential to understand the influence of these advertisements on the purchase of oral care products such as toothbrushes, toothpastes and mouthwashes. Gaining an insight can throw light on how some factors can be modified and how some parts of advertisements can be refined to create a better impact. This study has been conducted over a period of 6 months in the Department of Public Health Dentistry in, Rural Dental College, Loni. The study has highlighted the following: Most people do pay attention to advertisements; most people do not buy products based on the celebrities endorsing it; most people remain unaffected by a famous celebrity in an advertisement; popularity of an oral care product does make more people buy it; most people come around advertisements on television frequently; the catchiest factor in an oral care product advertisement were the brands people were familiar with or the brands they could trust; most people accepted that they sometimes judge a product by its advertisement; a few of the advertisements were remembered by most of the people; most people do skip/mute advertisements sometimes and most people claim that advertisements help them recall the product.

Keywords: advertisements, oral care products, mouthwashes, toothpastes, toothbrushes, dental floss, dental picks and sticks, oral irrigators, promotion

\section{Introduction}

In today's era, the awareness of maintaining an oral hygiene has increased and so has the awareness of using the suitable products. Most people no longer visit a shop and rely on the product offered to them by the shopkeeper. Awareness has increased and they now ask the shopkeeper to show them more variety and sometimes even specify their needs in order to get a suitable product. Consumers have more knowledge about the availability of products due to the widespread advertisements Companies have left no effort in order to promote their products and make them fanciful in the public eye. With an increase in competition, they frequently rely heavily on advertising to surpass other companies ${ }^{[1]}$. Some companies also offer various brands across many different markets and it is quintessential to allocate resources such that efficiency is not undermined ${ }^{[2]}$.

One medium which is used to a very large extent is advertisements. Different mediums are used, different approaches are made, all in an attempt to make their advertisements stand out and be unforgettable.

Companies try to create advertisements which provide the complete information of the product along with an increase in attractiveness that tempts the consumers. Thus, increasing interest in the product ${ }^{[3]}$.Consumers do make inferences regarding a product based on its visual appeal [4]. Information becomes accessible to a wide population and the manner in which the information influences the judgements depends on how the information is used ${ }^{[5]}$. Large sums of the marketing budget have been allocated for advertisements since it has been suggested that the liking for a product has a linear relationship with aesthetic appraisal ${ }^{[6]}$. 
Esthetical appraisal of products can differ and the difference depends on the appearance of the product and its context. Product is a critical element in the marketing mix ${ }^{[8]}$. Promotion along with place and price are the rest of the pillars that form the strong foundation which is required.

People tend to get bored by coming in contact with the same advertisements time and again. In order to overcome this many companies have started making advertisements with a theme of suspense. There is use of 'to be continued' in such adverts. Many companies also ensure that they change the advertisements from time to time in order to keep up the interest of the target audience.

Some companies make use of famous celebrities and some punchlines or catchy songs. It is useful to understand as to what will attract people towards an advertisement and the impact the adverts have on minds of the people. They also reinforce the much thought about face that smiles are a critical element in personal as well as professional life ${ }^{[9]}$.

Advertisements can be seen at various places. With the advent of social media and the digital era in the millennial age we should also pay very careful attention to the effect of the adverts on various applications and websites.

Thus, the aim of this study was to understand the influence which advertisements of oral health care products such as toothpastes, toothbrushes and mouthwashes have on the purchase of these products.

\section{Materials and Methods}

The urban population of Maharashtra is in high contact with advertisements wiz television, social media etc. From the morning newspaper to the hoardings on their way to work. From the advertisements in the digital media as they browse Instagram and Facebook to the advertisements on the radio and music playing applications. The cross-sectional survey was carried out in the Department of Public Health Dentistry at Pravara Institute of Medical Sciences, Loni for a period of six months.

The survey was created on an online survey application 'Survey Monkey' and its link was sent on various WhatsApp groups which contained the particular target audience along with a message requesting them to complete the survey. The inclusion criteria included people who were willing to participate in the study., the people who were residing in urban areas of Maharashtra, people who were literate and who had access to internet.

People who were unwilling to participate in the study, people who did not use oral health care products and people who resided in areas other than urban areas of Maharashtra were excluded from the study.

The consent was included with the questionnaire itself and people were given the advantage of complete anonymity.

The questionnaire had 10 questions which were objective in nature. People were allowed to answer each question by selecting a single option from those presented. Each participant completed the study and answered all the questions that were listed.

The results were gathered and the responses were entered in Microsoft Excel and analysed in SPSS windows version 16.0 (SPSS, Inc., Chicago. IL, USA). Descriptives and frequencies were analysed.

\section{Results}

The results of this study show that most people do pay attention to advertisements (47.62\%) however a few people pay attention to advertisements sometimes (41.27\%) and there were a few people who didn't pay attention to advertisements $(11.11 \%)$.

Most people do not buy products based on the celebrities endorsing it (65.08\%) while a few people however, do choose the product based on the celebrity endorsing it, sometimes (25.40\%) and there are a few section of the people who agree to buy oral care products based on the celebrities endorsing them (9.52\%).

Most people remain unaffected by a famous celebrity in an advertisement (46.03\%) but there are some people who get an impact that the company must be big $(23.81 \%)$ while a few of them even consider that the product is of a high quality (17.46\%) and an equal number of people feel that the product must be expensive or that the brand is facing intense competition (4.76\% respectively). A handful of people consider that the presence of a famous celebrity in an advertisement means that the product is not selling well (3.17\%).

Popularity of an oral care product does make more people buy it (42.86\%) whereas a small section of people may buy a product according to its popularity sometimes (34.97\%). Only a handful of people do not buy a product according to its popularity (22.22\%).

Most people come around advertisements on television frequently (88.89\%). Some people also view or hear advertisements on digital media (7.94\%). Newspaper is also a medium of advertisements people view advertisements frequently in $(3.17 \%)$ but, radio, magazine and hoarding didn't come across as sites people frequently view or hear advertisements in ( $0 \%$ respectively).

The catchiest factor in an oral care product advertisement were the brands people were familiar with or the brands they could trust $(44.44 \%)$. It was then followed by people liking product information in the advertisement (33.33\%). Some people even appreciated songs or catchy dialogues (14.29\%). Discounts and deals were liked by a few people (4.76\%). Some people chose celebrities and famous people being a catchy factor (3.17\%). None of the people who took the study found price information as a catchy factor ( $0 \%)$.

Most people accepted that they sometimes judge a product by its advertisement (47.62\%) whoever, there were people who said that they don't judge a product by its advertisement $(38.10 \%)$ and a few people accepted that they judge a product by its advertisement (14.29\%).

A few of the advertisements were remembered by most of the people (66.67\%) and some people accepted to be remembering advertisements very well (22.22\%) whilst a handful of people denied remembering advertisements (11.11\%).

Most people do skip/mute advertisements sometimes (66.13\%) while some of them skip or mute advertisements all the time $(24.15 \%)$. A few of them do not skip or mute advertisements (9.68\%).

Most people claim that advertisements help them recall the product $(42.86 \%)$ while some of them say that it creates a positive impression (39.68\%) and a handful of them think that advertisements create an interest or desire to purchase products $(17.46 \%)$.

Table 1: Frequency of the target audience choosing an oral care product based on the celebrity in the advertisement.

\begin{tabular}{|c|c|c|c|}
\hline Sr. No & Options & Answers & Percentage \\
\hline 1 & Always & 12 & $9.52 \%$ \\
\hline 2 & Never & 82 & $65.08 \%$ \\
\hline 3 & Sometimes & 32 & $25.40 \%$ \\
\hline
\end{tabular}


Table 2: Frequency of the target population remembering advertisements of oral products.

\begin{tabular}{|c|c|c|c|}
\hline Sr. No & Options & Answers & Percentage \\
\hline 1 & Very Well & 28 & $22.22 \%$ \\
\hline 2 & Never & 14 & $11.11 \%$ \\
\hline 3 & A Few of Them & 84 & $66.67 \%$ \\
\hline
\end{tabular}

Table 3: Frequency of the significance of a famous celebrity in an advertisement.

\begin{tabular}{|c|c|c|c|}
\hline Sr. No & Options & Answers & Percentage \\
\hline 1 & Product is of high quality & 22 & $17.46 \%$ \\
\hline 2 & It must be expensive & 6 & $4.76 \%$ \\
\hline 3 & Company must be big & 30 & $23.81 \%$ \\
\hline 4 & Brand is facing a lot of competition & 6 & $4.76 \%$ \\
\hline 5 & Product is not selling well & 4 & $3.17 \%$ \\
\hline 6 & Doesn't affect you & 58 & $46.03 \%$ \\
\hline
\end{tabular}

Table 4: Frequency of how advertisements affect the target population.

\begin{tabular}{|c|c|c|c|}
\hline Sr. No & Options & Answers & Percentage \\
\hline 1 & Recall & 54 & $42.86 \%$ \\
\hline 2 & Positive Impression & 50 & $39.68 \%$ \\
\hline 3 & Interest/Desire to Purchase & 22 & $17.46 \%$ \\
\hline
\end{tabular}

\section{Discussion}

It was revealed, in this study, that majority of the population pays attention to advertisements. Whereas, the second common response of the study sample was that they did pay attention to advertisements, but sometimes. Not paying attention to advertisements is considered as an option selected by only a few people.

A conclusion can be made, by the results obtained in this study, that this study sample has answered that they never select an oral care product based on the celebrity in the advertisement. This answer correlates with the findings by Sony Mathews ${ }^{[3]}$. In this study the second stand is the preference of people sometimes selecting products based on the celebrities in the advertisements.

Most of the study population tells that there is no effect of a celebrity in an advertisement. The second most finding aims at people assuming that the company must be big, trailing behind this response is people feeling that product is of high quality. Following this is an equal amount of people feeling that product is not selling well or it is expensive. The last response, which gained minimum interest is that the product is not selling well.

According to the answers of this study, popularity of an oral care product will make people buy the product. A few people have even cited that sometimes, they may buy product based on the popularity. The least frequent answer, in this study was a No. A study by Elena Delg depicts that brand trust is deep seated in the experience people have had with the brand and is indeed positively associated with brand loyalty ${ }^{[13]}$.

Advertisements are aired in various places and it is quintessential for us to understand where most of the advertisements are being watched. This helps us streamline our efforts to make the advertisement reach the target population. Also, this helps us gain focus on our approach in marketing. Television is still the reigning site where people tend to watch advertisements. It comes as no surprise that the second choice is digital media. Newspaper stands as the third choice.

Findings by Remziye Terkan have thrown light on the fact that creativity is needed to increase sales ${ }^{[1]}$. This study has established that brands which people trust is one of the most attractive features in an advertisement. This is followed by product information and then by catchy songs or dialogues. Discounts and deals are the second last option which people have selected and the least frequent option is the presence of celebrities and famous people.

“'Don't judge a book by its cover' that's what most of us have frequently heard. The same way it was imperative to understand whether people judge a product by its advertisement. The most frequent finding reveals that sometimes, people do judge a product by its advertisement. It has been suggested, by Janneke Bijlevens that liking for a product has a linear relationship with aesthetic appraisal ${ }^{[6]}$. Esthetical appraisal of products can differ and the difference depends on the appearance of the product and its context ${ }^{[7]}$. Findings by Benedikt Schnurr have marked that unfamiliar products are perceived as better quality when placed as attractive manner ${ }^{[8]}$

According to this survey, I can conclude that people remember a few of the advertisements of oral products. It may depend on the type of advertisements. Depending on whether the advertisements possess the factors they find catchy, or their favourite celebrity etc, there might be higher chances of them remembering the advertisements.

Television and radio offer an option to 'MUTE' or to 'Change The Channel'. Newspapers and Magazines offer an option to 'FLIP'. Digital Media can have varied options. Sometimes it is compulsory to watch the advertisement until you can reach your video, it has varied timings ranging from 5 seconds to 10 seconds. Some videos also offer an option, too view the advertisements for 5 seconds and then skip the remaining advertisement, if it doesn't hold any interest.

According to this study. a conclusion has been reached that most of the people tend to skip or mute advertisements sometimes. Lesser number of people always skip advertisements. And the least number of people don't skip or mute advertisements.

It is important to understand how advertisements affect people. This provides us an insight on what the advertisement is providing. In this study, most people say that advertisements help them recall the oral care products. This result is followed by people determining that oral care product advertisements create a positive impression. The least number of people consider that oral care product advertisement creates an interest or desire to purchase those products.

\section{Conclusion}

1. Most people pay attention to advertisements.

2. Most people don't buy products based on the celebrities endorsing it.

3. Most people remain unaffected by a famous celebrity in advertisements.

4. Popularity of a product does make people buy it.

5. The media in which advertisements are most watched is Television.

6. The most attractive factor in an advertisement is brands that people are familiar with or brands they can trust.

7. Most people judge a product by its advertisement.

8. Most people only remember a few advertisements.

9. Most people skip or mute advertisements.

10. The most frequent effect of advertisement is that they hall people recall a product.

\section{References}

1. Importance of Creative Advertising and Marketing According to University Students’ Perspective; Remziye 
Terkan; International Review of Management and Marketing 2014;4(3):239-246. ISSN: 2146-4405.

2. Aaker, David A. Managing Brand Equity. New York: Free Press. 1996. "Measuring Brand Equity Across Products and Markets 1991.

3. Effect of Celebrity Endorsement on Consumer Based Brand Equity: Toothpaste Industry; Sony Mathews.

4. The effect of context attractiveness on product attractiveness and product quality: the moderating role of product familiarity; Benedikt Schnurr \& Alexandra Brunner- Sperdin \& Nicola E. Stokburger-Sauer; Published online: 9 August 2016 \# The Author(s) 2016.

5. Bless H, Schwarz N. Mental construal and the emergence of assimilation and contrast effects: the inclusion/exclusion model. Advances in Experimental Social Psychology 2010;42:319-373.

6. Blijlevens J, Carbon CC, Mugge R, Schoormans JPL. Aesthetic appraisal of product designs: independent effects of typicality and arousal. British Journal of Psychology 2011;103(1):44-57.

7. Blijlevens J, Gemser G, Mugge R. The importance of being Bwell- placed $\wedge$ : the influence of context on perceived typicality and esthetic appraisal of product appearance. Acta Psychologica 2012;139(1):178-186.

8. Bloch PH. Seeking the ideal form: product design and consumer response. Journal of Marketing 1995;59(3):1629.

9. Influence of media in the choice of oral hygiene products used among the population of Madravoyal, Chennai, India; Anitha Logaranjani.

10. Delgado-Ballester Elena, Jose Luis Munuera-Alemán. "Does Brand Trust Matter to Brand Equity". Journal of Product \& Brand Management 2005;14(3):187-19. 